\title{
Alcohol and arterial wave reflections in middle aged and elderly men
}

\author{
M. J. C. A. van Trijp", W. J.W. Bos ${ }^{\dagger}$, Y.T. van der Schouw*, M. Muller", D. E. Grobbee ${ }^{*}$ and \\ M. L. Bots* \\ ${ }^{\star}$ University Medical Center Utrecht, Utrecht, ${ }^{\dagger}$ St. Antonius Hospital, Nieuwegein, the Netherlands
}

\begin{abstract}
Background Augmentation index (AIx) is a measure of arterial wave reflection, providing information on the workload of the heart. and is a possible marker for cardiovascular disease risk. The relation of alcohol consumption with cardiovascular disease (CVD) risk is U-shaped with a protective effect of moderate alcohol consumption. The relation of alcohol consumption level with AIx has not been widely investigated, which prompted this study of the relation of alcohol consumption with AIx in a population-based cohort of men aged $40-80$ years.
\end{abstract}

Methods Three hundred and seventy-four men (mean age 60.5 years) participated in this cross-sectional study. Alcohol consumption and smoking habits were determined through a validated questionnaire. Fasting blood samples were drawn and analyzed for glucose and lipid levels and AIx was estimated by radial applanation tonometry using the SphygmoCor Device. The resultant data were analyzed using linear regression models.

Results Age, height, heart rate, blood pressure, packyears, current smoking, presence of CVD and hypertension were independently related to AIx. The relation of alcohol consumption with AIx was U-shaped, with a significantly lower AIx in the group drinking $4-8$ glasses $/$ week (difference $=-2.91 \%, 95 \%$ CI $[-5 \cdot 65 ;-0 \cdot 18]$ ) relative to those drinking 0-3 glasses/week. Additional adjustment for current smoking did not change this relationship, but adjustment for pulse wave velocity attenuated the relation.

Conclusions In a population-based cohort of men aged 40-80 years the relation of alcohol consumption level with AIx was U-shaped, further expanding the evidence for vascular protective effects of moderate alcohol intake.

Keywords Alcohol, arterial wave reflections, augmentation index, men

Eur $\mathcal{F}$ Clin Invest 2005; 35 (10): 615-621

\section{Introduction}

The relation between alcohol consumption and its effects on the cardiovascular system appears to be U-shaped with a higher risk of cardiovascular (CVD) disease in non-drinkers

Julius Center for Health Sciences and Primary Care, University Medical Center Utrecht, Utrecht (M. J. C. A. van Trijp, Y. T. van der Schouw, M. Muller, D. E. Grobbee, M. L. Bots); Department of Internal Medicine, St. Antonius Hospital, Nieuwegein (W. J. W. Bos), the Netherlands.

Correspondence to: Dr M. L. Bots, MD, PhD, Julius Center for Health Sciences and Primary Care, University Medical Center Utrecht, Str. 6.131, Heidelberglaan 100/PO Box 85500, 3584 CX/3508 GA Utrecht, the Netherlands. Tel.: +31 30250 9352; fax: +31 30250 5485; e-mail: m.l.bots@umcutrecht.nl

Received 29 June 2005; accepted 19 August 2005 and heavy-drinkers and a protective effect in moderate drinkers [1]. The reduced risk of CVD with moderate alcohol consumption has been explained by an increase of HDL cholesterol [2], a decrease of inflammatory factors such as C-reactive protein [3] or an increase of fibrinolytic factors [4]. Several studies on the effect of measures of vascular structure have indicated that moderate alcohol consumption is related to reduced carotid intima media thickness [5] and that the relation with aortic stiffness, measured as pulse wave velocity (PWV), is J-shaped $[6,7]$. To further explore the relation of alcohol with functional vascular characteristics this study evaluated the relation of alcohol consumption level to AIx, as evidence on this issue is scarce $[7,8]$.

Augmentation index is a measure of arterial wave reflection, defined as the difference between central (i.e. aortic) early and reflected pressure peaks divided by pulse pressure [9]. The AIx provides information on workload for the heart and is a possible marker for CVD risk [10]. An increased AIx 
has been related to risk factors of CVD, such as elevated blood pressure, hypercholesterolaemia [11], diabetes [12], and smoking [13], and also an increased AIx has been related to prevalent CVD [10] and estimated CVD risk [14,15].

The primary aim of this study was to examine the relation of alcohol intake with AIx in a population-based cohort of men aged 40-80 years and explore which other risk factors were related to the AIx.

\section{Methods}

\section{Study design and population}

This was a cross-sectional, single-centre study of 400 men aged 40-80 years with a main research theme of endogenous hormones as determinants of frailty in middle aged and elderly men, as described elsewhere [16]. Subjects were recruited by mailing a letter to 770 female participants of an earlier study conducted by the Julius Center for Health Sciences and Primary Care [17], requesting whether the women knew of possible male volunteers in the age group 40-80 years. Through this method 240 men volunteered to participate and a further 1230 personal invitation letters were sent to male inhabitants of the city of Utrecht, the Netherlands, in the 40-80-year age group. The men were randomly selected from the municipal register and through this method a further 390 men volunteered to participate. After adjustment for age there was no difference in the characteristics of both populations. From the total of 630 men who volunteered for participation, 16 were excluded because they were not living independently and were not physically or mentally fit to visit the study centre. No additional healthrelated eligibility criteria were used. Of the remaining 614 men, 400 men were randomly selected to participate in the study, with equal numbers in each age-decade in the range from 40 to 80 years. The Medical Ethical Committee of the University Medical Center Utrecht approved the study and all participants gave written informed consent. Data collection took place at the outpatient clinic of the Julius Center between March 2001 and April 2002.

\section{Cardiovascular risk profile}

Blood pressure was measured twice in the morning, after a $10 \mathrm{~min}$ rest, in the right brachial artery (sitting position) with a semiautomated device (Dinamap 8100; Critikon Inc., Tampa, Finland). Mean systolic and diastolic blood pressures were calculated as the mean of the two blood pressure measurements. Pulse pressure (PP) was calculated as (SBP-DBP) and mean arterial pressure (MAP) was calculated as $(2 \star \mathrm{DBP}+\mathrm{SBP}) / 3$.

Height, weight and waist-to-hip ratios were measured with the participant in standing position wearing indoor clothes and no shoes. Smoking was estimated from self-report and categorized as 'current', 'former' and 'never smokers'. Alcohol intake was estimated using a validated food frequency questionnaire
$[18,19]$. Socio-economic status was recorded by life-long occupation in four levels: (1) scientific, (2) high-grade, (3) middle-grade and (4) low-grade profession. A medical doctor obtained information about the prevalence of diseases and medications being used from a specified medical history.

Fasting venous blood samples were drawn and analyzed. Total cholesterol (TC), and high-density-lipoprotein (HDL) cholesterol were determined using an automated enzymatic procedure (Synchron LX Systems, Beckman Coulter, Mijdrecht, The Netherlands). Low-densitylipoprotein (LDL) cholesterol was calculated using the Friedewald formula [20]. Insulin was measured using an IMMULITE 2000 Analyser (DPC, Los Angeles, CA). The lower limit of detection was $2 \mathrm{mU} \mathrm{L}^{-1}$ and interassay variation was $8 \cdot 6 ; 4 \cdot 8 ; 4 \cdot 4 ; 5 \cdot 1$ and $5 \cdot 4 \%$ at $14 ; 27 ; 86 ; 175$ and $354 \mathrm{mU} \mathrm{L}^{-1}$, respectively. Fasting blood glucose was determined by using the reagent-strip glucose oxidase method and glucose levels were assessed using a GlucoTouch reflectometer (LifeScan Inc., Benelux, Milpitas, CA). Venous whole blood was immediately applied to the test strip. The HOMA (Homeostasis Model Assessment) index, a measure of insulin resistance, was calculated as (fasting glucose $\star$ [fasting insulin/22.5]) [21].

Hypertension was defined as $\mathrm{SBP} \geq 140 \mathrm{mmHg}$ and/or $\mathrm{DBP} \geq 90 \mathrm{mmHg}$ and/or use of blood pressure lowering medication. Diabetes mellitus was defined as treatment with insulin or oral hypoglycaemic agents and/or fasting plasma venous glucose $>6.9 \mathrm{mmol} \mathrm{L}^{-1}$. Hyperlipidaemia was defined as treatment with lipid-lowering medication and/or serum total cholesterol $>6.5 \mathrm{mmol} \mathrm{L}^{-1}$. Presence of CVD was defined as presence of coronary artery disease, peripheral artery disease or stroke.

Carotid-femoral (aortic) pulse wave velocity (PWV) was measured as described previously [22].

\section{Measurement of augmentation index (AIx)}

Vascular measurements were performed using the SphygmoCor $^{\mathrm{TM}}$ Blood Pressure Analysis system (Sydney, Australia) by two experienced technicians involved in other studies $[6,22]$. Aortic pulse waveform, AIx and central aortic pressures were derived by applanation tonometry of the radial artery [23]. The radial pressure waveform was recorded non-invasively with a micro-manometer (Millar SPT-301, Millar Instruments; Houston, TX). The probe was held on the skin over the maximal arterial pulsation by hand and pressed down on the artery against the underlying bone. Ascending aortic pressure was derived from the central pressure waveform, using a generalized transfer function which is incorporated in the SphygmoCor device [24]. Finally, the AIx (the difference between early and late pressure peaks divided by pulse pressure) was calculated and expressed as a percentage.

\section{Data analysis}

Data on applanation tonometry measurements were available for 397 men. The data of four men were missing on 
Table 1 AIx and HDL-cholesterol in the study population by level of alcohol intake, adjusted for age, height, heart rate and MAP

\begin{tabular}{llcll}
\hline $\begin{array}{l}\text { Alcohol intake level } \\
\text { (glasses/week) }\end{array}$ & $n$ & $\begin{array}{l}\text { Alcohol intake } \\
\text { (glasses/week) }\end{array}$ & $\begin{array}{l}\text { AIx } \\
(\%)\end{array}$ & $\begin{array}{l}\text { HDL-cholesterol } \\
\left(\mathrm{mmol} \mathrm{L}^{-1}\right)\end{array}$ \\
\hline $0-3$ & 98 & $0 \cdot 9(0 \cdot 6)$ & $25 \cdot 8(1 \cdot 0)$ & $1 \cdot 21(0 \cdot 03)$ \\
$4-8$ & 88 & $5 \cdot 8(0 \cdot 7)^{\dagger}$ & $22 \cdot 8(1 \cdot 0)^{\star}$ & $1 \cdot 30(0 \cdot 04)$ \\
$9-19$ & 96 & $13 \cdot 7(0 \cdot 6)^{\dagger}$ & $23 \cdot 9(1 \cdot 0)$ & $1 \cdot 35(0 \cdot 03)^{\star}$ \\
$20-79$ & 92 & $31 \cdot 1(0 \cdot 7)^{\dagger}$ & $25 \cdot 6(1 \cdot 0)$ & $1 \cdot 43(0 \cdot 03)^{\dagger}$ \\
\hline
\end{tabular}

Data are expressed as mean (standard error of the mean).

${ }^{\star} P<0.05$ : compared with 1 st quartile $(0-3$ glasses/week).

${ }^{\dagger} P<0 \cdot 001$ : compared with 1 st quartile $(0-3$ glasses/week).

Table 2 Change in AIx (\%) per alcohol intake compared with very light drinkers

\begin{tabular}{llll}
\hline $\begin{array}{l}\text { Alcohol intake level } \\
\text { (glasses/week) }\end{array}$ & $N$ & Model A & Model B \\
\hline $0-3$ & 98 & Reference & Reference \\
$4-8$ & 88 & $-2 \cdot 91[-5 \cdot 65 ;-0 \cdot 18]^{\star}$ & $-2 \cdot 84[-5 \cdot 56 ;-0 \cdot 13]^{\star}$ \\
$9-19$ & 96 & $-1 \cdot 89[-4 \cdot 57 ; 0 \cdot 79]$ & $-1 \cdot 99[-4 \cdot 65 ; 0 \cdot 68]$ \\
$20-79$ & 92 & $-0 \cdot 12[-2 \cdot 82 ; 2 \cdot 58]$ & $-0 \cdot 49[-3 \cdot 20 ; 2 \cdot 22]$ \\
\hline
\end{tabular}

Values are linear regression coefficients [95\% confidence interval].

Model A: adjusted for age, height, heart rate and MAP.

Model B: adjusted for age, height, heart rate, MAP and current smoking.

${ }^{\star} P$-value $<0.05$.

alcohol intake level and for 19 men data were missing on one or more laboratory tests, leaving 374 subjects for the analyses. The AIx was calculated as [augmented pressure/ (central SBP - central DBP)] $\star 100$ [25], and was normally distributed. The clinical and biochemical characteristics of the study population were expressed as a mean $( \pm$ standard deviation, SD) or as a percentage. Relations of determinants with AIx were examined using linear regression analysis. First, crude relations of determinants with AIx were investigated and subsequently re-evaluated after adjustment for age, height heart rate and MAP. Second, the relation of alcohol with AIx was investigated in quartiles of alcohol consumption level to enable an assessment of the shape of a possible relation. Using ANOvA models, the AIx in each alcohol quartile was estimated and adjusted for age, height, heart rate and MAP, as these factors are related to AIx. To validate the self-reported data on alcohol consumption the HDL level was estimated in each quartile (Table 1). Finally, dummy variables were defined and relation of alcohol consumption level to AIx was estimated by linear regression analysis. There were no non-drinkers in this cohort, therefore the group consuming 0-3 alcoholic beverages/week was used as the reference group. First, the analysis was adjusted for age, height, heart rate and MAP (model A in Table 2) and, subsequently, the model was adjusted for current smoking because this factor was the sole determinant related to both AIx and alcohol intake level (model B). Finally, the model was adjusted for PWV because it is related to AIx and to alcohol intake [7].

To evaluate whether the association between alcohol intake level and AIx differed across prevalence of CVD, prevalence of hypertension, prevalence of diabetes, prevalence of hyperlipidaemia, age and physical activity, and multiplicative interaction terms were constructed and estimated using linear regression models. As all interaction terms were not significant $(P$-value $>0 \cdot 15)$, no stratified analyses are presented. Statistical analyses were performed using the statistical package SPSS-11.0 for Windows (Chicago, IL).

\section{Results}

The characteristics of the study population are summarized in Table 3.

All blood pressure components, age, height, heart rate, waist/hip ratio, smoking, presence of cardiovascular disease and presence of (or treatment for) hypertension were statistically significantly related to AIx (model A in Table 4). To investigate the independent relation of risk factors for cardiovascular disease the AIx was adjusted for age, height, heart rate and MAP. Mean arterial pressure was selected over systolic pressure or pulse pressure because it is stable along the arterial tree (model B in Table 4). A number of cardiovascular risk factors were borderline and significantly related to an increased AIx. These were elevated circulating insulin and low physical activity. No relation with serum lipids and HOMA-index was found, although PWV and AIx were significantly related the magnitude of the relation was modest (Spearman correlation was $0.21 P<0.001$ ).

Table 1 shows that HDL-cholesterol gradually increased with increasing levels of alcohol consumption, thus supporting 
Table 3 General characteristics of the study population $(n=374 \mathrm{men})$

\begin{tabular}{|c|c|}
\hline Age (years) & $60 \cdot 5(11 \cdot 3)$ \\
\hline $\mathrm{SBP}(\mathrm{mmHg})$ & $143(22)$ \\
\hline $\mathrm{DBP}(\mathrm{mmHg})$ & $81(10)$ \\
\hline $\mathrm{PP}(\mathrm{mmHg})$ & $62(18)$ \\
\hline $\mathrm{MAP}(\mathrm{mmHg})$ & $102(12)$ \\
\hline Height $(\mathrm{cm})$ & $178 \cdot 0(7 \cdot 3)$ \\
\hline Heart rate (beats $\min ^{-1}$ ) & $70(12)$ \\
\hline Weight $(\mathrm{kg})$ & $83 \cdot 1(12 \cdot 2)$ \\
\hline Waist/hip ratio & $0.97(0.06)$ \\
\hline Glucose $\left(\mathrm{mmol} \mathrm{L}^{-1}\right)$ & $5 \cdot 9(1.5)$ \\
\hline Insulin $\left(\mathrm{mU} \mathrm{L}^{-1}\right)$ & $8 \cdot 6(5 \cdot 8)$ \\
\hline HOMA-index $(n=357)$ & $2 \cdot 39(2 \cdot 23)$ \\
\hline Triglycerides $\left(\mathrm{mmol} \mathrm{L}^{-1}\right)$ & $1.39(0.66)$ \\
\hline Total cholesterol $\left(\mathrm{mmol} \mathrm{L}^{-1}\right)$ & $5 \cdot 7(1 \cdot 0)$ \\
\hline LDL-cholesterol $\left(\mathrm{mmol} \mathrm{L}^{-1}\right)$ & $3.9(0.9)$ \\
\hline HDL- cholesterol $\left(\mathrm{mmol} \mathrm{L}^{-1}\right)$ & $1 \cdot 3(0 \cdot 3)$ \\
\hline Smoking (number of pack years) & $16 \cdot 5(21 \cdot 0)$ \\
\hline Smoking, current $(\%)$ & $24 \cdot 6$ \\
\hline Smoking, former $(\%)$ & $53 \cdot 2$ \\
\hline Smoking, never (\%) & $22 \cdot 2$ \\
\hline Socio-economic-status, low (\%) & $15 \cdot 8$ \\
\hline Socio-economic-status, middle (\%) & $29 \cdot 4$ \\
\hline Socio-economic-status, high (\%) & $35 \cdot 3$ \\
\hline Socio-economic-status, scientific (\%) & $19 \cdot 5$ \\
\hline Alcohol consumption (units/week) & $12 \cdot 8(13 \cdot 2)$ \\
\hline Physical activity score & $18 \cdot 2(7 \cdot 5)$ \\
\hline Cardiovascular disease $(\%)$ & $17 \cdot 1$ \\
\hline Diagnosis of hypertension (\%) & $25 \cdot 9$ \\
\hline $\begin{array}{l}\text { Hypertension, treated or } \\
\qquad \mathrm{SBP} \geq 140 \mathrm{mmHg} \text { or DBP } \geq 90 \mathrm{mmHg}(\%)\end{array}$ & $62 \cdot 6$ \\
\hline $\begin{array}{l}\text { Diabetes treated and } / \text { or } \\
\text { glucose }>6.9 \mathrm{mmol} \mathrm{L}^{-1}(\%)\end{array}$ & $11 \cdot 0$ \\
\hline $\begin{array}{l}\text { Hyperlipidaemia, treated and/or } \\
\text { total cholesterol }>6.5 \mathrm{mmol} \mathrm{L}^{-1}(\%)\end{array}$ & $33 \cdot 4$ \\
\hline Aortic PWV $\left(\mathrm{m} \mathrm{s}^{-1}\right)(n=355)$ & $9 \cdot 4(2 \cdot 5)$ \\
\hline Augmentation Index $(\%)$ & $24 \cdot 6(10 \cdot 4)$ \\
\hline
\end{tabular}

SBP, systolic blood pressure; DBP, diastolic blood pressure; $\mathrm{PP}$, pulse pressure; MAP, mean arterial pressure; PWV, pulse wave velocity.

Values are means with standard deviations in parentheses, or percentages.

the validity of the self-reported data on alcohol consumption. The relation of alcohol consumption with AIx was U-shaped. Men drinking 0-3 units/week (the reference group) had an AIx that was similar to the group with the highest drinking level. Subjects drinking 4-8 units/week had an AIx that was $2.91 \%$ lower than the reference group, with a $95 \%$ CI $[-5 \cdot 56 ;-0 \cdot 13]$ (model $\mathrm{A}$ in Table 2$)$. As current smoking was the only determinant related to both AIx and alcohol intake, the model was adjusted for current smoking (model $\mathrm{B}$ in Table 2). Socio-economic-status (SES), weight, total cholesterol and HDL-cholesterol were only related to alcohol intake level and not to AIx. Thus, these factors could not confound the relation of alcohol intake with AIx and were therefore not considered in the multivariable model. In an earlier report [7], a J-shaped relation of PWV with alcohol intake was noted. As PWV is related to AIx, we further adjusted the model for PWV and this attenuated the strength of the relation for $\pm 12 \%$, indicating that part of the relation of alcohol consumption with AIx is explained by aortic stiffness.

\section{Discussion}

This cross-sectional study among men aged 40-80 years showed that the relation of alcohol consumption with AIx is U-shaped and has a significantly lower AIx for subjects drinking 4-8 units/week of alcoholic in comparison with subjects drinking 0-3 units/week.

To appreciate these results, some aspects of the present study should be discussed. First, alcohol consumption was assessed from a questionnaire which may have introduced selective under-reporting in the heavy-drinking groups. However, as HDL-cholesterol increased with increasing alcohol consumption, which is consistent with other studies [2], we assume that the self-reported data are valid. Second, the AIx was estimated using a generalized transfer function to calculate aortic pressure waves from radial artery pressure waves [24]. This transfer function has been validated [2628]. However, studies comparing 'true' invasively measured aortic AIx and estimated aortic AIx from applanation tonometry at the radial artery indicated that the estimated AIx is sometimes under [24,29] or overestimated [30], and correlations varied from relatively good [29] to relatively poor [30]. Therefore, the transfer function has become subject to debate [31-34]. The previously mentioned studies $[24,29,30]$ were not clear whether the difference between the 'true' and the 'estimated' values were a random phenomenon or owing to a shift in the distribution. If the first case was true it would lead to an under-estimation of the 'true' associations (bias towards the null-value), but if the latter case was true the associations would be valid, but the magnitude of the associations would be too high or too low. The study assumes that if the transfer function generated complete random values, no relations of risk factors for cardiovascular disease with AIx would have been found but this does not hold true in this study. Third, as AIx and other factors were measured on a single occasion there was no possibility to correct for within-subject biological variation. This may reflect average exposure to risk factors less precisely than repeated measurements (regression to the mean phenomenon) and may lead to an underestimation of the associations. An advantage of this study is that it provides data from a relatively large population-based cohort and a broad range of age groups.

To the authors knowledge, only three studies have been performed into the relation of alcohol consumption to AIx. Mahmud and Feely studied both acute and chronic effects of alcohol consumption on AIx in a study population of 223 men and 101 women in the age range of $18-86$ years [8]. A decrease of AIx $90 \mathrm{~min}$ after consumption of $500 \mathrm{~mL}$ of red wine was found, which was independent of the effect of alcohol on blood pressure. Furthermore, AIx was higher in men with a chronic excessive $\left(>210 \mathrm{~g} \mathrm{week}^{-1}\right)$ 
Table 4 Relation of several characteristics with augmentation index

\begin{tabular}{|c|c|c|}
\hline Determinant & Model A & Model B \\
\hline Age & $0 \cdot 22[0 \cdot 13 ; 0 \cdot 31]^{\dagger}$ & \\
\hline SBP & $0 \cdot 11[0 \cdot 07 ; 0 \cdot 16]^{\dagger}$ & \\
\hline DBP & $0 \cdot 13[0.02 ; 0.23]^{\dagger}$ & \\
\hline PP & $0 \cdot 12[0.07 ; 0 \cdot 18]^{\dagger}$ & \\
\hline MAP & $0 \cdot 17[0 \cdot 09 ; 0 \cdot 25]^{\dagger}$ & \\
\hline Height & $-0.44[-0.58 ;-0 \cdot 30]^{\dagger}$ & \\
\hline Heart rate & $-0 \cdot 14[-0 \cdot 23 ;-0 \cdot 06]^{\dagger}$ & \\
\hline Weight & $-0.05[-0 \cdot 14 ; 0 \cdot 04]$ & $0.08[-0.01 ; 0 \cdot 17]^{\ddagger}$ \\
\hline Waist/hip ratio & $25 \cdot 1[7 \cdot 0 ; 43 \cdot 2]^{\dagger}$ & $13 \cdot 5[-5 \cdot 5 ; 32 \cdot 4]$ \\
\hline Glucose & $0 \cdot 55[-0 \cdot 17 ; 1 \cdot 28]$ & $0.54[-0 \cdot 15 ; 1 \cdot 22]$ \\
\hline Insulin $^{\star}$ & $0 \cdot 15[-0.03 ; 0 \cdot 34]$ & $0 \cdot 17[-0 \cdot 05 ; 0 \cdot 39]^{\ddagger}$ \\
\hline HOMA-index $(n=357)$ & $0 \cdot 38[-0 \cdot 10 ; 0 \cdot 86]$ & $0 \cdot 26[-0 \cdot 19 ; 0 \cdot 70]$ \\
\hline Triglycerides & $0 \cdot 81[-0 \cdot 79 ; 2 \cdot 41]$ & $0 \cdot 49[-0.99 ; 1.96]$ \\
\hline Total cholesterol & $-0.68[-1 \cdot 72 ; 0 \cdot 37]$ & $-0.53[-1 \cdot 49 ; 0 \cdot 43]$ \\
\hline LDL-cholesterol & $-0 \cdot 98[-2 \cdot 14 ; 0 \cdot 18]$ & $-0.67[-1 \cdot 74 ; 0 \cdot 39]$ \\
\hline HDL-cholesterol & $-0 \cdot 07[-3 \cdot 26 ; 3 \cdot 12]$ & $-0 \cdot 55[-3 \cdot 46 ; 2 \cdot 36]$ \\
\hline Number of pack years & $0.09[0.04 ; 0.14]^{\dagger}$ & $0.06[0.01 ; 0.11]^{\dagger}$ \\
\hline Current smoking & $1 \cdot 09[-1 \cdot 37 ; 3 \cdot 55]$ & $2 \cdot 82[0.54 ; 5 \cdot 11]^{\dagger}$ \\
\hline Socio-economic status & $-0 \cdot 70[-1 \cdot 79 ; 0 \cdot 39]$ & $-0.06[-1.07 ; 0.95]$ \\
\hline Physical activity score $(n=370)$ & $-0.08[-0 \cdot 22 ; 0 \cdot 06]$ & $-0.09[-0 \cdot 22 ; 0 \cdot 04]^{\ddagger}$ \\
\hline Cardiovascular disease yes/no & $4.36[1.57 ; 7 \cdot 14]^{\dagger}$ & $2 \cdot 62[-0.05 ; 5 \cdot 28]^{\ddagger}$ \\
\hline Diagnosis of hypertension yes/no & $3 \cdot 97[1 \cdot 18 ; 6 \cdot 76]^{\dagger}$ & $1 \cdot 12[-1 \cdot 53 ; 3 \cdot 78]$ \\
\hline $\begin{array}{l}\text { Hypertension, treated or SBP } \geq 140 \mathrm{mmHg} \\
\text { or } \mathrm{DBP} \geq 90 \mathrm{mmHg}\end{array}$ & $5 \cdot 14[3 \cdot 00 ; 7 \cdot 27]^{\dagger}$ & $2 \cdot 81[-0 \cdot 12 ; 5 \cdot 75]^{\ddagger}$ \\
\hline Diabetes treated or glucose $>6.9 \mathrm{mmol}$ & $1 \cdot 66[-1 \cdot 73 ; 5 \cdot 05]$ & $1 \cdot 80[-1 \cdot 37 ; 4 \cdot 97]$ \\
\hline Hyperlipidaemia treated and/or total cholesterol $>6.5$ & $-0 \cdot 49[-2 \cdot 74 ; 1 \cdot 76]$ & $-0 \cdot 44[-2 \cdot 49 ; 1 \cdot 61]$ \\
\hline PWV $(n=355)$ & $0 \cdot 80[0 \cdot 42 ; 1 \cdot 18]^{\dagger}$ & $0 \cdot 35[-0 \cdot 14 ; 0 \cdot 85]$ \\
\hline
\end{tabular}

SBP, systolic blood pressure; DBP, diastolic blood pressure; PP, pulse pressure; MAP, mean arterial pressure; PWV, pulse wave velocity.

Model A: association of determinant with AIx, crude; Model B: association of determinant with AIx adjusted for age, height, heart rate and MAP.

*Persons with diabetes excluded leaving 354 subjects for the analyses.

Values are linear regression coefficients [95\% confidence interval], expressing change in AIx (in percentage) per 1 unit change in risk factor.

${ }^{\dagger} P$-value $<0.05$.

${ }^{\ddagger} P$-value $\geq 0 \cdot 05$ and $\leq 0 \cdot 10$.

alcohol intake (AIx $12 \pm 2 \%$ ) than those with a normal $\left(<210 \mathrm{~g} \mathrm{week}^{-1}\right.$ ) alcohol intake (AIx $\left.5 \pm 1 \%\right)$. However, this difference was not statistically significant when adjusted for blood pressure. No relation was found in women between alcohol consumption and AIx [8]. Dosedependent results were not presented. Greenfield et al. [35] investigated the relation between life-style factors and AIx in a population of 684 female twins (age range 18 71 years), but no information was provided about the relation between alcohol and AIx, although the subjects drinking 15 or more alcoholic beverages/week had a significantly higher AIx than the abstainers. Sierksma et al. studied in a dose-dependent manner the relation of alcohol consumption and AIx among healthy post-menopausal women (aged 50-74 years). No relation was observed with AIx [7]. However, a J-shaped relation of alcohol consumption with PWV in the same study population as the current analysis was observed [7].

The results of this study confirm previous findings that AIx is associated with age, height [36], heart rate [37] and mean arterial pressure [38]. No relation with lipids levels was found that agree with findings from studies among middle-aged and elderly hypertensives $[39,40]$, but contrast with the findings from Wilkinson et al. [11] among 68 subjects with hypercholesterolaemia (mean age $51 \pm 10$ years, 25 men) and 68 controls. The findings that smoking is related to an increased AIx is in agreement with other studies $[13,41]$. Furthermore, two studies on the acute effects of (passive) smoking on AIx indicated that smoking is related to an increase in AIx $[42,43]$, even though these studies were conducted in young healthy subjects (20-30 years).

Mechanisms underlying the cardioprotective effects of moderate alcohol consumption may be related to alcoholinduced changes in serum lipids, lipoproteins, blood clotting proteins, platelets, inflammatory cytokines, and insulin resistance and are described in detail elsewhere [44].

In conclusion, the results of this study in a populationbased cohort of men aged 40-80 years show a U-shaped relation of alcohol consumption with AIx with a significantly lower AIx for subjects drinking 4-8 alcoholic units/week. The findings provide additional support for the vascular protective properties of moderate alcohol consumption. 


\section{References}

1 Grobbee DE, Rimm EB, Keil U, Renaud S. Alcohol and the cardiovascular system. In: McDonald I, editor. Health Issues Related to Alcohol Consumption. Oxford: Blackwell Sciences Ltd;1999.pp. 125-79.

2 Rimm EB, Williams P, Fosher K, Criqui M, Stampfer MJ. Moderate alcohol intake and lower risk of coronary heart disease: Meta-analysis of effects on lipids and haemostatic factors. BMF 1999;319:1523-8.

3 Sierksma A, van der Gaag MS, Kluft C, Hendriks HF. Moderate alcohol consumption reduces plasma C-reactive protein and fibrinogen levels; a randomized, diet-controlled intervention study. Eur f Clin Nutr 2002;56 (11):1130-6.

4 Hendriks HF, Veenstra J, Velthuis-te Wierik EJ, Schaafsma G, Kluft C. Effect of moderate dose of alcohol with evening meal on fibrinolytic factors. BMF 1994;308 (6935):1003-6.

5 Mukamal KJ, Kronmal RA, Mittleman MA, O’Leary DH, Polak JF, Cushman $\mathrm{M}$ et al. Alcohol consumption and carotid atherosclerosis in older adults: the cardiovascular health study. Arterioscler Thromb Vasc Biol 2003;23 (12):2252-9.

6 Sierksma A, Lebrun CE, van der Schouw YT, Grobbee DE, Lamberts SW, Hendriks HF et al. Alcohol consumption in relation to aortic stiffness and aortic wave reflections: a cross-sectional study in healthy postmenopausal women. Arterioscler Thromb Vasc Biol 2004;24:342-8.

7 Sierksma A, Muller M, van der Schouw YT, Grobbee DE, Hendriks HF, Bots ML. Alcohol consumption and arterial stiffness in men. $\mathcal{F}$ Hypertens 2004;22 (2):357-62.

8 Mahmud A, Feely J. Divergent effect of acute and chronic alcohol on arterial stiffness. Am f Hypertens 2002;15 (3):240-3.

9 Davies JI, Struthers AD. Pulse wave analysis and pulse wave velocity: a critical review of their strengths and weaknesses. f Hypertens 2003;21 (3):463-72.

10 Weber T, Auer J, O’Rourke MF, Kvas E, Lassnig E, Berent R et al. Arterial stiffness, wave reflections, and the risk of coronary artery disease. Circulation 2004;20;109 (2):184-9.

11 Wilkinson IB, Prasad K, Hall IR, Thomas A, MacCallum H, Webb DJ et al. Increased central pulse pressure and augmentation index in subjects with hypercholesterolemia. f Am Coll Cardiol 2002;39 (6):1005-11.

12 Wilkinson IB, MacCallum H, Rooijmans DF, Murray GD, Cockcroft JR, McKnight JA et al. Increased augmentation index and systolic stress in type 1 Diabetes Mellitus. QFM 2000;93 (7):441-8.

13 Mahmud A, Feely J. Effect of smoking on arterial stiffness and pulse pressure amplification. Hypertension 2003;41 (1):183-7.

14 Nurnberger J, Keflioglu-Scheiber A, Opazo Saez AM, Wenzel RR, Philipp T, Schafers RF. Augmentation index is associated with cardiovascular risk. F Hypertens 2002;20 (12):2407-14.

15 Duprez DA, Kaiser DR, Whitwam W, Finkelstein S, Belalcazar A, Patterson $\mathrm{R}$ et al. Determinants of radial artery pulse wave analysis in asymptomatic individuals. Am $\mathcal{F}$ Hypertens 2004;17 (8):647-53.

16 Muller M, den Tonkelaar I, Thijssen JH, Grobbee DE, van der Schouw YT. Endogenous sex hormones in men aged 40-80 years. Eur f Endocrinol 2003;149 (6):583-9.

17 van der Schouw YT, Pijpe A, Lebrun CE, Bots ML, Peeters $\mathrm{PH}$, van Staveren WA et al. Higher usual dietary intake of phytoestrogens is associated with lower aortic stiffness in postmenopausal women. Arterioscler Thromb Vasc Biol 2002;22 (8):1316-22.
18 Ocke MC, Bueno-de-Mesquita HB, Goddijn HE, Jansen A, Pols MA, van Staveren WA et al. The Dutch EPIC Food Frequency Questionnaire. I. Description of the questionnaire, and relative validity and reproducibility for food groups. Int f Epidemiol 1997;26 (Suppl. 1):S37-48.

19 Ocke MC, Bueno-de-Mesquita HB, Pols MA, Smit HA, van Staveren WA, Kromhout D. The Dutch EPIC Food Frequency Questionnaire. II. Relative validity and reproducibility for nutrients. Int $\mathcal{F}$ Epidemiol 1997;26 (Suppl. 1):S49-58.

20 Friedewald WT, Levy RI, Fredrickson DS. Estimation of the concentration of low-density lipoprotein cholesterol in plasma, without use of the preparative ultracentrifuge. Clin Chem 1972;18 (6):499-502.

21 Matthews DR, Hosker JP, Rudenski AS, Naylor BA, Treacher DF, Turner RC et al. Homeostasis model assessment: Insulin resistance and $\beta$-cell function from plasma fasting blood sugar and insulin concentrations in man. Diabetologia 1985;28:412-9.

22 Oren A, Vos LE, Uiterwaal CS, Grobbee DE, Bots ML. Aortic stiffness and carotid intima-media thickness: two independent markers of subclinical vascular damage in young adults? Eur $\mathcal{F}$ Clin Invest 2003;33 (11):949-54.

23 O'Rourke MF, Gallagher DE. Pulse wave analysis. f Hypertens 1996;14:S147-S157.

24 Chen CH, Nevo E, Fetics B, Pak PH, Yin FC, Maughan WL et al. Estimation of central aortic pressure waveform by mathematical transformation of radial tonometry pressure. Validation of generalized transfer function. Circulation 1997;95 (7):1827-36.

25 Oliver JJ, Webb DJ. Noninvasive assessment of arterial stiffness and risk of atherosclerotic events. Arterioscler Thromb Vasc Biol 2003;23 (4):554-66.

26 O'Rourke MF, Pauca AL. Augmentation of the aortic and central arterial pressure waveform. Blood Press Monit 2004; 9 (4):179-85.

27 Pauca AL, O'Rourke MF, Kon ND. Prospective evaluation of a method for estimating ascending aortic pressure from the radial artery pressure waveform. Hypertension 2001;38 (4):932-7.

28 Gallagher D, Adji A, O'Rourke MF. Validation of the transfer function technique for generating central from peripheral upper limb pressure waveform. Am f Hypertens 2004; 17 (11 Part 1):1059-67.

29 Segers P, Qasem A, De Backer T, Carlier S, Verdonck P, Avolio A. Peripheral 'oscillatory' compliance is associated with aortic augmentation index. Hypertension 2001;37 (6):1434-9.

30 Hope SA, Tay DB, Meredith IT, Cameron JD. Use of arterial transfer functions for the derivation of aortic waveform characteristics. f Hypertens 2003;21 (7):1299-305.

31 O'Rourke MF, Nichols WW. Use of arterial transfer function for the derivation of aortic waveform characteristics. J Hypertens 2003;21 (11):2195-7.

32 Hope SA, Tay DB, Meredith IT, Cameron JD. Reply. f Hypertens 2003;21 (11):2197-9.

33 Avolio AP, O'Rourke MF. Applicability and benefit of arterial transfer functions. F Hypertens 2003;21 (11):2199-200.

34 Hoeks AP. Reply. F Hypertens 2003;21 (11):2200-1.

35 Greenfield JR, Samaras K, Campbell LV, Jenkins AB, Kelly PJ, Spector TD et al. Physical activity reduces genetic susceptibility to increased central systolic pressure augmentation: a study of female twins. F Am Coll Cardiol 2003;42 (2):264-70.

36 Smulyan H, Marchais SJ, Pannier B, Guerin AP, Safar ME, London GM. Influence of body height on pulsatile arterial hemodynamic data. F Am Coll Cardiol 1998;31 (5):1103-9. 
37 Wilkinson IB, MacCallum H, Flint L, Cockcroft JR, Newby DE, Webb DJ. The influence of heart rate on augmentation index and central arterial pressure in humans. F Physiol 2000;525 (Part 1):263-70.

38 Wilkinson IB, MacCallum H, Hupperetz PC, van Thoor CJ, Cockcroft JR, Webb DJ. Changes in the derived central pressure waveform and pulse pressure in response to angiotensin II and noradrenaline in man. F Physiol 2001;530 (3):541-50.

39 Saba PS, Roman MJ, Longhini C, Scorzoni D, Pini R, Devereux R et al. Carotid intimal-medial thickness and dtiffness are not affected by hypercholesterolemia in uncomplicated essential hypertension. Arterioscler Thromb Vasc Biol 1999; 19 (11):2788-94.

40 Dart AM, Gatzka CD, Cameron JD, Kingwell BA, Liang YL, Berry KL et al. Large artery stiffness is not related to plasma cholesterol in older subjects with hypertension. Arterioscler Thromb Vasc Biol 2004;24 (5):962-8.

41 Fennessy F, Casey RG, Bouchier-Hayes D. Peripheral and central arterial haemodynamic interactions are early abnormalities in young male cigarette smokers. Eur $\mathcal{F}$ Vasc Endovasc Surg 2003;25 (2):152-8.

42 Mahmud A, Feely J. Effects of passive smoking on blood pressure and aortic pressure waveform in healthy young adults. Influence of gender. Br F Clin Pharmacol 2004;57 (1):37-43.

43 Vlachopoulos C, Alexopoulos N, Panagiotakos D, O'Rourke MF, Stefanadis C. Cigar smoking has an acute detrimental effect on arterial stiffness. Am f Hypertens 2004;17 (4):299-303.

44 Lucas DL, Brown RA, Wassef M, Giles TD. Alcohol and the cardiovascular system research challenges and opportunities. f Am Coll Cardiol 2005;45 (12):1916-24. 